\title{
EN TORNO A UNA FUERZA CENTRÍPETA FALTANTE
}

Jaime Glaría *

* Departamento de Electrónica, Universidad Técnica Federico Santa María, Valparaíso, Chile. 


\section{RESUMEN}

La cooperación y la convergencia en la educación superior se contraponen con las apetencias fragmentarias y centrífugas que nos impartimos en la educación

\section{ABSTRACT}

Cooperation and convergence in higher education defy the fragmentary and centrifugal eager-ness we teach ourselves through education 


\title{
EN TORNO A UNA FUERZA CENTRÍPETA FALTANTE
}

\section{A MODO DE PRÓLOGO}

Me ha sido encargado un aporte para este espacio que atiende a la cooperación y a la convergencia en la educación superior.

Como tengo pocos antecedentes más que los recabados dictando cursos, me veo en el apuro de Francisco de Quevedo y me permito partir buscando aliento en su soltura:

\author{
Un soneto me manda hacer Violante; \\ en mi vida me he visto en tal aprieto. \\ Catorce versos dicen que es soneto; \\ burla burlando van tres delante. \\ Yo pensé que no hallara consonante, \\ y estoy en la mitad de otro cuarteto, \\ mas si me veo en el primer terceto \\ no hay cosa en los cuartetos que me espante. \\ Por el primer terceto voy entrando \\ $y$ aun parece que entré con pie derecho \\ pues fin con este verso le estoy dando. \\ Ya estoy en el segundo y aun sospecho \\ que estoy los trece versos acabando. \\ Contad si son catorce, y está hecho.
}

\section{CONTRATIEMPO}

La cooperación y la convergencia en la educación superior se contraponen con las apetencias descomedidas por lo fragmentario y centrífugo que nuestra sociedad exhibe en demasiados ámbitos, 
incluidos los universitarios, unidas a una desconfianza radical perceptible hasta en nuestra fórmula contemporánea para las despedidas cordiales: "cuídate".

La fruición por lo fraccionado y estrecho se manifiesta de partida en los cursos de nuestra educación superior, como largos sometimientos a nombres especializados que desquician la comunicación en común con el pretexto de los modos modernos, el cual constituye otro manifiesto de la misma fruición.

\section{UNA EVIDENCIA}

Los nombres especiales son impuestos en casi todos los cursos, adobados con eufemismos y alocuciones sobre la precisión, la calidad y el rigor científicos. Pero en ello no se considera el costo que esa apetencia impone a los menesterosos de conocimientos.

Como ilustración magra y elegida más o menos al azar, valga la lista siguiente de nombres incluidos en un curso de fundamentos de la Termodinámica para estudiantes de ingeniería por un libro universitario nacional, que existe, pero no se revela para no exacerbar lo que ya hay de injusto en la elección: "alrededor", "atmósfera", "banco de trabajo", "bomba", "bomba adiabática", "bomba de calor", "Btu", "caloría", "calidad (de un vapor)", "calidad del calor", "calidad del trabajo", "calor", "calor latente", "calor sensible", "cantidad", "cantidad extensiva", "cantidad intensiva", "capacidad calorífica", "capacidad calorífica específica a presión constante", "capacidad calorífica molar", "capacidad calorífica molar a presión constante", "capacidad calorífica molar a volumen constante", "carrera", "ciclo de Carnot", "ciclo de Carnot inverso", "ciclo de Rankine", "ciclo de Diesel", "ciclo dual", "ciclo de Otto", "cilindrada", "coeficiente de adiabate", "coeficiente de desempeño", "coeficiente de variación de la entalpía con la presión", "coeficiente de variación de la temperatura debido al cambio de la presión", "coeficiente isobárico de variación del volumen con la temperatura", "coeficiente isotérmico de compresibilidad", "coeficiente isotérmico de variación de la energía interna con el volumen", "coeficiente de Joule-Thompson", "coeficiente de expansión térmica", "coeficiente virial", "componente", "composición", "compresión adiabática", "compresión isotérmica", "compresor", "compresor reciprocante", "condición crítica", "condición restrictiva", 
"consecuencia termodinámica", "constante gravitacional", "contacto térmico", "correcciones D", "degradación de la energía", "diagrama de Mollier h-s", "diagrama P-h", "diagrama P-s", "diagrama P-v", "diagrama T-s", "diagrama termodinámico", "diferencia infinitesimal", "difusor", "dimensión", "ecuación de Antoine", "ecuación de ClausiusClapeyron", "ecuación de continuidad", "ecuación de estado", "ecuación de Redlich-Kwong", "ecuación de Riedel", "ecuación de van der Waals", "ecuación generalizada del factor de compresibilidad", "ecuación universal de los gases ideales", "ecuación virial", "ecuaciones de Maxwell", "eficiencia isentrópica", "eficiencia térmica", "energía acumulable", "energía almacenable", "energía configuracional", "energía de Gibbs", "energía de Helmholtz", "energía externa", "energía interna", "energía total", "entalpía", "equilibrio térmico", "escala termodinámica de temperatura", "estado", "estado de agregación", "estado de equilibrio", "etapa activa", "expansión adiabática", "expansión isentálpica", "expansión isotérmica", "expansor", "factor de compresibilidad", "factor de compresibilidad crítico", "factor de compresibilidad ponderado", "fase", "fluido incompresible", "fluido termométrico", "fuente-sumidero de calor", "función", "función específica", "función extensiva", "función intensiva", "gas ideal”, "gas recalentado"...

Ante tamaña desmesura, que no es privativa de estos fundamentos termodinámicos, no vale recostarse en exculpaciones varias ni apartar, jocosamente, a quienes se llenan de nombres, llamándolos nominalistas.

\section{GÉNESIS}

La colocación de nombres es de data más larga que la ciencia.

Así, entre 2.15 y 2.22 del Génesis de la Biblia de Jerusalén, se lee: “... Tomó, pues, Yahveh Dios al hombre y lo dejó en el jardín del Edén, para que lo labrara y lo cuidase. Y Dios impuso al hombre este mandamiento: 'De cualquier árbol del jardín puedes comer; mas del árbol de la ciencia del bien y del mal no comerás; porque el día que comieres de él, morirás sin remedio'. Dijo luego Yahveh Dios: 'No es bueno que el hombre esté solo...'. Y Yahveh Dios formó del suelo todos los animales del campo y todas las aves del cielo, y los llevó ante el hombre para ver cómo las llamaba, y para que cada ser viviente tuviese 
el nombre que el hombre le diera. El hombre puso nombres a todos los ganados, a las aves del cielo y a todos los animales del campo... Entonces Yahveh Dios hizo caer un profundo sueño sobre el hombre, el cual se durmió. Y le quitó una de las costillas, rellenando el vacío con carne. De la costilla que Yahveh Dios había tomado del hombre, formó una mujer...".

\section{BABEL}

El conocimiento de algunas consecuencias también es de data larga.

Entre 10.32 y 11.9 del Génesis de la misma versión bíblica, por ejemplo, se lee que a partir de las familias de los hijos de Noé “... se dispersaron los pueblos por la tierra después del diluvio. Todo el mundo era de un mismo lenguaje e idénticas palabras. Al desplazarse la humanidad desde oriente, hallaron una vega en el país de Senaar y allí se establecieron. Entonces se dijeron el uno al otro: "Ea, vamos a fabricar ladrillos y a cocerlos al fuego". Así el ladrillo les servía de piedra y el betún de argamasa. Después dijeron: 'Ea, vamos a edificarnos una ciudad y una torre con la cúspide en los cielos; y hagámonos un renombre, por si nos desperdigamos por toda la faz de la tierra'. Bajó Yahveh a ver la ciudad y la torre que habían edificado los humanos, y dijo Yahveh: 'He aquí que todos son un solo pueblo con un mismo lenguaje; y este es el comienzo de su obra. Ahora nada de cuanto se propongan les será imposible. Ea, pues, bajemos y una vez allí confundamos su lenguaje, de modo que no entienda cada cual el de su prójimo'. Y desde aquel punto los desperdigó Yahveh por toda la faz de la tierra, y dejaron de edificar la ciudad. Por eso se la llamó Babel, porque allí embrolló Yahveh el lenguaje de todo el mundo...".

\section{TÉCNICAS}

Tomar distancia con citas bíblicas, donde se conjugan lo viejo con lo religioso, seguramente es un pecado doble para la avidez de fragmentos -en este caso laicos y actuales- de que hablamos.

Volvamos a los estudiantes de ingeniería, cuyas preocupaciones superan hoy, por mucho, al cocimiento de ladrillos. 
Para actuar en la realidad con destreza, para variar lo real diestramente hay que saber qué cosas obedecen a la voluntad, qué otras dependen de ellas, qué otras dependen de éstas y así, sucesivamente, extendiendo las acciones.

"Técnica" fue el nombre de la destreza para los griegos; "arte" lo fue para los romanos.

Las técnicas, las de la ingeniería y otros oficios prácticos -como la medicina- son conocimientos adquiridos para variar la realidad directa o indirectamente, anticipando lo que va a pasar.

"Acto técnico" es el que se apoya conscientemente en un saber para predecir las variaciones resultantes del acto mismo.

Predecir es decir antes, no decir con nombres especiales.

En las predicciones termodinámicas que necesitan aprender los estudiantes de ingeniería, el manejo de algunos datos vale más que la pronunciación de nombres. Dicho frontalmente: lo que vale es el entendimiento sosegado de algunos fenómenos y de las representaciones matemáticas que, con una dosis de suerte, los desbrozan.

Tales fenómenos y representaciones tienen troncos gruesos, que son comunes para casi todos los cursos duros de los estudios de ingeniería, y que las listas de nombres y los planes de carrera suelen centrifugar dándoles apariencia arbustiva y espinosa.

\section{EDUCACIÓN}

Los párrafos anteriores nos ponen frente a otra manifestación habitual de nuestra apetencia fragmentaria: la segregación entre lo cualitativo y lo cuantitativo; entre lo elocuente y lo numérico; entre lo humanista y lo técnico.

El caso es que lo numérico lleva en la humanidad varios milenios $y$, cuando se da la oportunidad, resulta ser sustantivamente mejor que otros medios para predecir. Su segregación de "lo humano" es un 
surrealismo allegado a deseos de impredecibilidad, para creer en un libre albedrío irrestricto. Expresado de otra manera: se aparta lo numérico como si atentase contra la dignidad humana.

Pero un libre albedrío irrestricto exigiría un beneplácito mágico por parte de la realidad, si no se la niega, y la impredecibilidad otorgaría una vacuidad sórdida a la educación.

Si ésta tiene alguna excusa valedera para el gasto enorme que conlleva, es que hay dosis de predecibilidad por doquier, y que el descubrimiento o la fabricación de conocimientos para predecir y actuar diestramente en lo real ha tomado a la humanidad esfuerzos grandes durante decenas de siglos.

\section{ECONOMÍA EN LA EDUCACIÓN}

"El hombre se ocupa y preocupa de la enseñanza por una razón tan simple como seca y tan seca como lamentable: para vivir con firmeza, desahogo y corrección hace falta saber una cantidad enorme de cosas, y el niño, el joven, tienen una capacidad limitadísima de aprender. Esta es la razón... Hoy más que nunca el exceso mismo de riqueza cultural y técnica amenaza con convertirse en una catástrofe para la humanidad, porque a cada nueva generación le es más difícil o imposible absorberla. No hay más remedio que volverse ahora contra esa inmensidad y usar el principio de economía, por lo pronto, como un hacha. Primero, poda inexorable. ¿Cómo determinar el conjunto de enseñanzas que han de constituir el torso o mínimum de Universidad? Sometiendo la muchedumbre fabulosa de los saberes a una doble selección: $1^{\circ}$ quedándose solo con aquellos que se consideren estrictamente necesarios para la vida del hombre que hoy es estudiante (...); $2^{\circ}$ esto que ha quedado por juzgarlo estrictamente necesario, tiene que ser reducido a lo que de hecho puede el estudiante aprender con holgura y plenitud".

Esas palabras no son modernas, sino de Ortega y Gasset ${ }^{1}$. Sigan estas otras: "Ha llegado a ser un asunto urgentísimo e inexcusable de

1 Ortega y Gasset, José, Misión de la Universidad, Editorial Espasa Calpe, Madrid, España, 1936, cap. III. 
la humanidad inventar una técnica para habérselas adecuadamente con la acumulación de saber que hoy posee. Si no encuentra maneras fáciles para dominar esa vegetación exuberante quedará el hombre ahogado por ella. Sobre la selva primaria de la vida vendrá a yuxtaponerse esta selva secundaria de la ciencia, cuya intención era simplificar aquella. Si la ciencia puso orden en la vida, ahora será preciso poner también orden en la ciencia, organizarla -ya que no es posible reglamentarla-, hacer posible su perduración sana. Para ello hay que vitalizarla, esto es, dotarla de una forma compatible con la vida humana que la hizo y para la cual fue hecha. De otro modo -no vale recostarse en vagos optimismos- la ciencia se volatilizará, el hombre se desinteresará de ella (...) La necesidad de crear vigorosas síntesis y sistematizaciones del saber (...) irá fomentando un género de talento científico que hasta ahora sólo se ha producido por azar: el talento integrador. En rigor, significa éste -como ineluctablemente todo esfuerzo creador- una especialización; pero aquí el hombre se especializa precisamente en la construcción de una totalidad (...) El movimiento que lleva a la investigación a disociarse indefinidamente en problemas particulares, a pulverizarse, exige una regulación compensatoria -como sobreviene en todo organismo saludablemediante un movimiento de dirección inversa que contraiga y retenga en un rigoroso sistema la ciencia centrífuga"2.

\section{UNA FUERZA CENTRÍPETA FALTANTE}

Para compensar la centrifugación de las enseñanzas, para integrar conocimientos, estamos algo faltos de fuerza centrípeta.

Sin embargo, es insensato no hacernos cargo de los costos que la avidez por los fragmentos impone a los menesterosos de saberes.

La pérdida de tiempo, esfuerzo y dinero que provoca entre los estudiantes, y la impronta de estrechez que ha puesto entre los egresados, están a la vista de quien quiera mirarlas.

En este espacio que atiende a la cooperación y a la convergencia en la educación superior, conviene considerar que la educación que

2 Ibid., cap. V. 
nos impartimos no nos colabora, y que sólo la variaremos con alguna destreza sacando fuerza de la flaqueza.

\section{A MODO DE EPÍLOGO}

Terminemos.

Aunque la cuenta no dé catorce versos, ni lo escrito dé para soneto, por aliento de Quevedo: ya está hecho. 